\title{
Os pactos dos direitos do homem
}

\author{
J. Canuto Mendes de Almeida \\ (Catedrático de Direito Judiciário Penal)
}

1. A Onu, como não se ignora, compõe-se de órgãos permanentes e de órgãos periódicos. Os permanentes ligam-se às atividades do Secretariado Geral, e funcionam, uns, em caráter, por assim dizer, de agentes de Poder Executivo da instituição, e, outros, em caráter auxiliar, técnico ou consultivo, da Assembléia Geral, que se reune anualmente, e das Comissões, em que ela se reparte, no desempenho das respectivas funções, por assim dizer, legislativas.

2. Dentre os órgãos permanentes contam-se o Conselho Econômico e Social e a Comissão de Direitos do Homem, que lhe é subordinada, os quais prepararam, e a Assembléia Geral aprovou, a 10 de dezembro de 1948, a conhecida Declaração Universal dos Direitos do homem, como - usemos das expressões de seu preâmbulo — "ideal comum a atingir por todos os povos e nações, afim de, tendo sempre presente ao espírito esta Declaração, esforçaremse todos os individuos e todos os órgãos da sociedade, mediante o ensino e a educação, por desenvolverem o respeito a êsses direitos e liberdades e por assegurar, através de medidas progressivas de ordem nacional e internacional, seu reconhecimento e sua aplicação universais e efetivas, tanto dentre mesmo as populações dos Estados Membros quanto dentre as dos territórios postos sob a jurisdição dêles".

Dentre as medidas progressivas de ordem internacional, entendeu, logo em seguida, a Assembléia Geral, que a $O n u$, deveria estimular os Estados Membros à celebração de so- 
lene e decidido ato internacional, capaz de garantir ou, ao menos, de criar condições conducentes a garantir o efetivo respeito, por tôdas as nações e por todos os povos, às prerrogativas contidas na aludida Declaração Universal dos Direitos do Homem. Dessa deliberação generosa surgiu a tarefa, dentre outras, a que, faz poucos anos, se entregam a Comissão dos Direitos do Homem e o Conselho Econômico e Social, de elaboração da minuta do modêlo de Pacto dos Direitos Humanos, que, apreciada oportunamente pela Assembléia Geral, há de ser recomendada à vinculação internacional positiva, isto é, à adoção de Estados contratantes. No desempenho dessa árdua tarefa, a Comissão e o Conselho, comunicam a Assembléia Geral, cada ano, as conclusões até então conquistadas; e, cada ano, a Assembléia Geral emite opinião sôbre tais conclusões, bem como encaminha sugestões ou recomendações, sôbre o assunto, destinadas à consideração da Comissão dos Direitos do Homem e do Conselho Econômico e Social, durante os trabalhos subsequentes de elaboração da referida minuta do modêlo do Pacto.

Quem, como o autor, pôde surpreender, em meio, o fio dêsse laborioso mister, como testemunha e como participante, em nome do Brasil, dos debates e das deliberações da terceira Comissão (uma das seções em que se desdobrou a VIII Assembléia Geral da Onu, como tôdas se desdobram) pode contar em que ponto então colheu, por assim dizer, um instantâneo do dinâmico trabalho e referir alguns aspectos mais interessantes do assunto, os quais mais preocuparam as diversas delegações, em 1953.

A agenda dos trabalhos da Terceira Comissão compreendia: 1) sôbre atividades do Alto Comissariado das Nações Unidas para os Refugiados, apreciação do Relatório do Comissário (a), de memorandum do Secretário Geral da Onu (b) e da conveniência de manter-se ou extinguir-se êsse Alto Comissariado; 2) assistência técnica para o desenvolvimento e a salvaguarda dos direitos da mulher; 3) 
assistência técnica para a prevenção da discriminação das minorias e sua proteção; 4) desenvolvimento dos direitos políticos da mulher, nos territórios onde não são plenamente reconhecidos; 5) programa de uma ação prática no domínio social das Nações Unidas e Agências Especializadas; 6) prova da existência de trabalho forçado; 7) medidas relativas à solução pacífica do problema dos prisioneiros de guerra; 8) apreciação do relatório do Conselho Econômico e Social, e de seus desdobramentos, dentre os quais o "informe da Comissão dos Direitos Humanos", acerca de seu nono período de sessões. Nêsse informe é que se compendiam os dados sôbre quanto e como, até o ano anterior, havia a Onu cuidado da elaboração da almejada minuta.

A Comissão de Direitos Humanos, em seu nono periodo de sessões, de 7 de abril a 30 de maio de 1953 , realizadas no Palácio das Nações, em Genebra, ocupara-se, sobretudo, em redigir os Projetos de Pactos Internacionais de Direitos Humanos e Medidas de Aplicação. A essa altura, já estava deliberado que, ao invés de um, dois deveriam ser êles: o Pacto de Direitos Econômicos, Sociais e Culturais e o Pacto de Direitos Civis e Políticos; bem como estava também assentado que se deveria adicionar a êles, como garantia de execução, cláusulas relativas a "medidas de aplicação". A Comissão reunira, em tais sessões, como seus membros, delegados da Austrália, Bélgica, Chile, Egito, Estados Unidos, Filipinas, França, India, Libano, Paquistão, Polônia, Inglaterra e Irlanda, Ucrânia, Suécia, Rússia, Uruguai e Iugoslávia, sob a presidência do delegado da França, Renê Cassin.

O labor dêsse ano, como já acontecera no anterior, baseara-se principalmente em projetos primitivos, preparados pela Comissão e em instruções da Assembléia Geral e do Conselho Econômico e Social. Haviam êstes solicitado: $1^{\circ}$ ) que se preparassem dois projetos, um sôbre direitos civis e políticos, e outro sốbre direitos econômicos, 
sociais e culturais, ambos com o maior número possível de disposições similares, especialmente quanto às informações dos Estados sôbre a aplicação dos pactos; $2^{\circ}$ ) que se difinissem, melhor do que nos projetos anteriores, os direitos e suas limitações, com a maior precisão possivel; $\left.3^{\circ}{ }^{\circ}\right)$ que se redigissem melhor os artigos sôbre direitos econômicos, sociais e culturais, segundo sugestão de alguns Estados membros e de organismos especializados; $4 .^{\circ}$ ) que se consignasse, de modo explícito, o reconhecimento da igualdade de homens e mulheres; $5 .^{\circ}$ ) que se inserisse dispositivo acerca do direito de livre determinação dos povos e nações, nos têrmos antes pautados pela Assembléia Geral; $\left.6^{\circ} .^{\circ}\right)$ que se estudasse, para se inserir nos pactos ou em protocolos separados, o assunto das petições de pessoas ou de organizações não oficiais, sôbre violações dos pactos; $7 .^{\circ}$ ) que se apreciassem, na redação, várias proposições e "documentos básicos de trabalho" da Assembléia Geral; 8. ) que se inserissem cláusulas relativas às reservas e seus efeitos; $9 .^{\circ}$ ) que se estudasse um artigo referente aos Estados federais, afim de se prepararem recomendações capazes de assegurar respeito aos pactos, por parte das unidades federadas, e de facilitar, nesse particular, as respectivas soIucoões constitucionais nacionais; $100^{\circ}$ ) que se incluísse um artigo sôbre a extensão da aplicabilidade dos pactos a todos os Estados metropolitanos signatários e a todos os territórios, autônomos ou não, em fideicomisso ou coloniais, administrados, que sejam, por Estados metropolitanos.

Outrossim, a Comissão, no seu anterior periodo de sessões, o oitavo, de 1952, não podendo concluir a tarefa, transferira vários assuntos à apreciação do nono periodo, com as devidas informações.

Além disso, haviam sido encaminhados à Comissão observações dos Estados Membros e de organismos especializados, bem como memoranduns e notas do Secretário Geral. 
E, afinal, a União das Repúblicas Socialistas Soviéticas, por seu delegado membro da Comissão, apresentara o seguinte projeto de resolução:

\section{"La Comissión de Derechos Humanos.}

Tomando nota de que durante el estudio de los artículos sobre los derechos civiles, políticos, económicos, sociales y la preparación de los dos proyectos de pacto con arreglo a la resolución 543 VI) de la Asamblea General del 5 de febrero de 1952 y a la resolución 440 (XIV) del 30 de junio de 1952 del Consejo Económico y "Social, ha vuelto a manifestarse en la forma más evidente que "el goce de las libertades cívicas y políticas y el de los derechos económicos, sociales y culturales están vinculados entre sí y se condicionam mutuamente", como lo reconoció la Asamblea General en su resolución 421 (V) del 4 de diciembre de 1951;

Considerando que la división del proyecto de Pacto de Derechos Humanos en dos pactos separados (el Pacto de Derechos Civiles y Políticos y el Pacto de Derechos Económicos y Sociales) es artificial e injustificada y puede debilitar la significación internacional de estos documentos,

Pide al Consejo Económico y Social que sugiera a la Asamblea General revisar su resolución 543 (VI)".

Esse projeto foi repelido, em votação nominal, por 9 votos (Austrália, Bélgica, China, Estados Unidos, França, India, Suécia, Inglaterra, Uruguai), contra 6 (Chile, Egito, Polônia, Ucrânia, Rússia, Iugoslávia), e uma abstenção (Filipinas). 
De tudo isso resultaram os projetos provisórios dos dois pactos, os quais ainda pendem de conclusão definitiva e de apreciação e aprovação da Assembléia Geral.

3. O texto dos dispositivos aprovados, então, pela Comissão, do Projeto de Pacto dos Direitos Econômicos, Sociais e Culturais, compunha-se de dezesseis artigos, dedicados: à livre determinação, para todos os povos e tôdas as nações, sôbre seu estatuto político, econômico. social e cultural, compreendendo-se nêsse direito "a soberania permanente sôbre suas riquezas e recursos naturais" (art. $1^{\circ}$ ); ao compromisso de envidar todos os recursos disponiveis para lograr a plena efetividade dos direitos reconhecidos no Pacto, e isso "mediante disposições legislativas, bem como por outros meios", e de garantir seu exercício "sem qualquer distinção de raça, cor, sexo, idioma, religião, opinião política ou de outra índole, origem nacional ou social, posição econômica, nascimento ou qualquer outra condição social" (art. 2..$^{\circ}$ ); ao compromisso de assegurar igualdade entre homens e mulheres, no gôzo dos mesmos direitos (art. $3 .^{\circ}$ ); ao reconheciriento de que os direitos garantidos pelo Pacto não podem sofrer limitações senão em virtude de lei, e, apenas, na medida compatível com a natureza dêsses direitos e com o exclusivo objeto de promover o bem estar geral de uma sociedade democrática" (art. $4^{\circ}{ }^{\circ}$ ); à proscrição de interpretações do Pacto capaz de autorizar, a Estado, a grupo ou a indivíduos, destruição ou redução indevida de direitos ou liberdades nele reconhecidas, ou de direitos humanos fundamentais, vigentes em face de leis, regulamentos, costumes, ou convenções, sob pretexto de omitidos no Pacto (art. 5..$^{\circ}$; ao direito de livre trabalho, adotadas, pelos Estados contratantes, medidas destinadas a sua plena efetividade e, especialmente, programas, normas e téenicas de constante desenvolvimento econômico e de total e produtivo emprego, em condições essecuratórias das liberdades políticas e econômicas fundamentais da 
pessoa humana (art. $6^{\circ}$ ); ao direito a condições equitativas e satisfatórias de trabalho, dentre as quais segurança e higiene, salário mínimo, salário justo, salário especifico igual, e sem distinção de sexo, descanso, utilização do tempo livre, limitação razoável das horas de trabalho, férias periódicas remuneradas (art. $7 .^{\circ}$ ); ao direito, de qualquer pessoa, de fundar sindicatos locais, nacionais ou internacionais, e de filiar-se a sindicatos de sua escôlha, para proteger seus interêsses econômicos e sociais" (art. $8^{\circ}$ ); ao direito de seguro social (art. $9 .^{\circ}$ ); à proteção à maternidade, à gestante, às crianças e aos adolescentes, vedados os trabalhos prejudiciais, sob sanção penal, bem como à proteção à família, e ao livre consentimento no matrimônio (art. 10. $0^{\circ}$; ao direito de alimentar-se, de vestir-se e de morar ( $\operatorname{art} .11 .^{\circ}$ ); ao direito a nível de vida adequado e a contínua melhora das condições de existência (art. 12. ${ }^{\circ}$ ); ao direito a satisfatórias condições de saúde, adotadas, pelos Estados contratantes, medidas destinadas a sua plena efetividade e, especialmente, relativas à redução ‘a mortalidade infantil, à sanidade das crianças, à melhoria da alimentação, da moradia e da higiene do ambiente social, à prevenção e ao tratamento das enfermidades cpidêmicas, endêmicas ou de outra índole, e à assistência médica (art. $13 .^{\circ}$ ); ao direito à educação, com o reconhecimento, pelos Estados contratantes, de que "a educação deve fomentar o pleno desenvolvimento da personalidade e o respeito aos direitos e liberdades fundamentais, bem como a supressão do ódio racial, ou de outra índole", de que a educação, outrossim, deve difundir "a compreensão, a tolerância e a amizade entre tôdas as nações e grupos raciais, étnicos ou religiosos, assim como o desenvolvimento das atividades das Nações Unidas para a manutenção da paz" e de que a educação deve, enfim, "capacitar tôda pessoa a participar efetivamente de uma sociedade livre"; ao mesmo direito de educação, entendendo-se que o ensino primário há de ser obrigatório e gratuito, o se- 
cundário, inclusive o técnico e o profissional, e o superior devem ficar ao alcance de todos e ser, gradualmente, gratuitos, à base do mérito pessoal, e que se há de propiciar educação fundamental, quanto possível, às pessoas carentes, ao todo ou em parte, de instrução primária"; à liberdade, de pais ou de tutores, de escolher escolas para filhos e pupilos, e de lhes dar educação religiosa (arts. 14 e 15); ao direito de participar da vida cultural e dos benefícios do progresso científico e de suas aplicações, adotadas medidas de conservação, incentivo e difusão da ciência e da cultura, e de respeito à liberdade de investigação científica e da atividade criadora". (art. 16).

Nos preâmbulos, as expressões usadas foram as mesmas, assim redigidas, tanto no frontespício do Pacto de Direitos Econômicos, Sociais e Culturais, quanto no Pacto dos Direitos Civis e Políticos:

\section{“Preâmbulo 10}

Los Estados Partes en el presente Pacti, Considerando que, conforme a los principios enunciados en la Carta de las Naciones Unidas, la libertad, la justicia y la paz en el mundo tienen por base el reconocimiento de la dignidad inherente a todos los miembros de la familia humana y de sus derechos iguales e inalienables,

Reconociendo que estos derechos se derivam de la dignidade inherente a la persona humana,

Reconociendo que, con arreglo a la Declaración Universal de Derechos Humanos, no puede realizarse el ideal del hombre libre, en el disfrute de las libertades civiles y politicas y liberado del temor y de la miseria, a menos que se creen condiciones que permitan a cada persona gozar de sus derechos civiles y políticos, tanto como de sus derechos económicos, sociales y culturales, 
Considerando que la Carta de las Naciones Unidas impone a los Estados la obligación de promover el respeto universal y efectivo de los derechos y libertades humanos,

Comprendiendo que el individuo, por tener deberes respecto de otros individuos y de la comunidad a que pertenece, tiene la obligación de esforzarse por la consecución y la observancia de los derechos reconocidos en este Pacto.

Convienen en los articulos siguintes:..."

Quanto ao Pacto dos Direitos Civis e Políticos, o respectivo projeto comportara 438 artigos, sôbre ampla matéria: do direito de todos os povos ou de tôdas as nações de determinarem livremente seu estatuto político, econômico, social e cultural, com permanente soberania sôbre suas riquezas e recursos naturais (art. 1); da igualdade de todos os individuos, quanto às garantias de direitos, sem distinção de raça, côr, sexo, idioma, religião, opinião política ou de outra indole, origem nacional ou social, posição econômica, nascimento ou qualquer outra condição social; de interposição de efetivo recurso judiciário contra viola. ções de direitos, garantindo-se efetivo respeito a seu provimento (art. 2); da igualdade civil e política de homens e mulheres (art. 3); da excepcional e limitada suspensão de garantias resultantes do Pacto (art. 4); da proscrição de conduta, fundada no Pacto, capaz de, por expediente de interpretação, resultar em destruição ou redução de direitos e liberdades nele consignados, ou de direitos fundados em leis, regulamentos e costumes, ou convenções, e, entretanto, omitidos no Pacto (art. 5); do direito à vida, disciplina da imposição da pena de morte e de sua execução (art. $6 .^{\circ}$ ); da proibição da tortura e da crueldade, bem como da sujeição, sem livre consentimento, a experiencias médicas e científicas (art. $7^{\circ}$ ); da proibição da escravidão, do tráfico de escravos, da servidão, do trabalho 
forçado ou obrigatório (art. 8. $^{\circ}$ ); das prisões processuais arbitrárias (art. 9. ${ }^{\circ}$ ); do regime penitenciário (art. 10); da proibição de prisão por dívidas (art. 11); do direito de livre circulação e de residência (art. 12) ; disciplina da expulsão do estrangeiro (art. 13); garantias processuais judiciárias (art. 14); irretroatividade da lei penal, salvo em benefício do réu (art. 15); direito à personalidade jurídica (art. 16); direito de inviolabilidade da vida privada, de domicílio, de correspondência, de honra e de reputação, e à proteção da lei contra as violações (art. 17); direito à liberdade de pensamento, de conciência e de religião, salvo as limitações! legais estatuídas no interêsse da ordem, da saúde e da moral públicas, dos direitos e liberdades fundamentais de todos (art. 18); direito à liberdade de expressão, especialmente, de informações, sem consideração de fronteiras, salvo as limitacõoes legais estatuídas no interêsse do respeito aos direitos e à reputação dos outros ou da segurança nacional, da ordem, da saúde e da moral públicas (art. 19); direto de reunião pacífica, feitas as mesmas ressalvas (art. 20); direito de livre associação, e, especialmente, de livre sindicalização para proteger interêsses, feitas ainda as mesmas ressalvas, acrescidas de "restrições legais ao exercício de tal direito (de livre associação) pelos membros das fôrças armadas ou da polícia", e respeitadas as cláusulas do Convênio sôbre a liberdade Sindical e a Proteção do Direito de Sindicalização, de 1948, pelos Estados que nele foram partes (art. 21); direito a livre matrimônio e a constituir família, em têrmos de igualdade de direitos e obrigações dos cônjuges (art. 22); direitos políticos, de participar da direção dos assuntos públicos, direta ou indiretamente, de votar e de ser votado, em eleiçães, por sufrágio universal, voto secreto e livre, e. acesso, a todos, às funções públicas de seu país (art. 23); direito de igualdade perante a lei, proibida qualquer discriminação de raça, côr, sexo, língua, religião, opinião, origem nacional ou social, posição econômica, nascimento 
ou qualquer outra condição social (art. 24); direito de minorias (art. 25); proibição legal de propaganda em favor da hostilidade nacional, racial ou religiosa que constitua incitação ao ódio e à violência (art. 26); estabelecimento de uma Comissão de Direitos Humanos, organizada segundo têrmos do Pacto (arts. 27 a 49), subordinada ao Conselho Econômico e Social, assessorado, em caráter consultivo, quando necessário, pela Côrte Internacional de Justiça, a qual, também, julgará em última instância, as reclamações sôbre violações dos direitos humanos (arts. 43 a 48 ).

As normas de direito nacional não devem distinguirse das normas de direito internacional, editadas pelos organismos internacionais, por seu conteúdo, variável, segundo acidentes de tempo, lugar, desenvolvimento econômico e social, circunstâncias ocasionais, como períodos de guerra ou de revolução, mas pelas suas consequências, se respeitadas (cumprimento da norma) ou se violadas (sanções).

No moderno direito público distingue-se a lei substancial da lei formal segundo os pontos de vista, respectivamente, da matéria, ou conteúdo, e da forma. Qualquer assunto pode constituir matéria da norma de lei, nos limites da competência constitucional dos órgãos de emissão da norma, sem que reste dúvida acerca do poder que tem o legislador de editá-la, contraposto ao poder de polícia ou de administração dos órgãos executivos. Disso resulta que a lei não se define pela natureza de seu conteúdo mas pelo processo de sua emissão, em atinência à autoridade legislativa de quem a emite. Desde que a norma se edita como lei e por quem pode fazer a lei, lei é. Desde que quem a fêz foi o legislador, lei é.

Isso não significa, entretanto, que, à base dessas considerações de processo legislativo, que dão maior relevância aos aspectos formais da lei do que a seu conteúdo, inexista um critério de matéria, para discernir o elemento 
específico da lei. Ninguém pode ser obrigado a fazer ou a deixar de fazer alguma coisa sinão em virtude de lei. Lei é a votada pelo poder legislativo. Os' povos devem dispor de si mesmos, e, portanto, a lei deve ser feita pelo povo, através de seus representantes. Tais princípios fundamentais atestam que há uma matéria específica reservada, pela sua natureza, ao legislador. Essa matéria é a das obrigações de fazer ou não fazer alguma coisa. Só a lei pode inovar no âmbito das obrigações e, consequentemente, dos direitos que às obrigações correspondem. Uma norma que não modifica essa ordem de direitos e de obrigações, no agregado estatal interno, não precisa ser lei para ter validade política. Pode ser regulamento, pode ser ato administrativo. $O$ que, como se vê, não importa em que possa também ser lei, porque emitida mediante norma do poder legislativo. De modo que as leis, cuidem ou não de matéria especifica, a saber, inovação na ordem normativa dos direitos, mediante inovação no âmbito das obrigações de fazer ou de deixar de fazer alguma coisa, que dão base a correspondentes direitos, são leis, sob o ponto de vista formal, que é o que interessa ao direito público moderno. Explica-se que assim seja, por causa da influência do pensamento filosófico do racionalismo dos séculos anteriores ao nosso, que, acentuando a antítese entre liberdade e autoridade, fundiu-as na sintese da democracia, consistente em admitir-se a legitimidade da sujeição dos homens a normas de autoridade apenas se editadas por êles mesmos, diretamente (plebiscito) ou indiretamente (regime representativo). Lei é, em suma, norma de conduta auto imposta. As minúcias constitucionais exprimem problemas e soluções de técnica, na realização dêsses princípios.

Mas, perguntava-se e ainda se pergunta: limita-se o poder que tem os povos de disporem de si próprios? A resposta do jusnaturalismo, de tôdas as colorações e de tôdas as intensidades, no campo filosófico, foi positiva. 
A unidade cristã do mundo, em recuados séculos, proclamara-o, sancionando o preceito mediante um sistema de coação - adequado à época - em que se misturaván contingentes e resíduos de ordem religioso-sentimental e de ordem político-econômica. 0 desmembramento da cristandade, reforçando o poder de cada unidade estatal, teria destruído as bases daquele sistema de sanções, substituindo-o, necessàriamente, através de tôdas as revoluções ante absolutistas, pelas declarações de direitos que os soberanos não poderiam inovar sem o consentimento dos governados (princípio democrático) e de direitos invioláveis, que nem mesmo os governados, em qualquer tempo e lugar, poderiam consentir em que fôssem restringidos, porque ínsitos na natureza humana (direitos fundamentais). A era dos absolutismos passou. Mas a pergunta, para a qual se pede resposta, continua de pé: limita-se o poder que tem os povos de disporem de si próprios, isto é, podem os povos arbitràriamente, e sem restrições, votar leis restritivas de todos e quaisquer direitos? Não. É essa a resposta, para os que aceitam que a organização política da humanidade, o sistema de fôrça coativa em que ela se cifra, não se legitima senão como meio de felicidade do homem. Portanto, a justiça das leis há de repousar sempre na consideração de que, em última análise, ela há de respeitar o homem. O homem era, no século do individualismo, o indivíduo. Hoje, o homem é o indivíduo, como expressão da humanidade. Seus direitos não se medem pela bitola de sua determinada pessoa, mas pela bitola da pessoa humana, indeterminadamente, de que êle é exemplar. Nisso consiste a consideração de ordem social que vem alterando os textos das declarações nacionais de direitos. Quais sejam os direitos fundamentais da pessoa humana, individuais ou sociais, é pesquisa de elaboração filosófica e sociológica, já adiantada, e, específicamente, de alta política. Essa alta política, na lógica do movimento constitucionalista contemporâneo, pode encontrar, no sistema tipo 
norte-americano, um modo de extrair da teoria para a prática legislativa e administrativa, o respeito dos direitos do homem, através do princípio de hierarquia das normas constitucionais sôbre as normas ordinárias. Se é certo que na ordem constitucional interna a definição dos direitos fundamentais é do arbítrio político do legislador constitucional, êsse arbítrio cessa na ordem filosófica ou científica, sob justas limitações opostas pelos teóricos da verdade política, e, igualmente, na ordem objetiva da consciência moral humana, em suas manifestações superiores, especialmente, como as do sentimento religioso, da sensibilidade artística, das intuições reveladas atraves do senso de julstiça das multidões e da obra de sistematização jurídica dêsses mesmos dados objetivos, realizada pelos juristas, doutrinàriamente, através de difusão de suas idéias, filosóficas ou sociológicas, e pràticamente através das conversações e decisões internacionais. Se é certo que se proclamam os direitos fundamentais por existentes, declará-los e respeitá-los é de interêsse humano. Cada homem e, portanto, todos os homens, sem distinção, podem e devem zelar, no estado de civilização moderna, pelo respeito dos direitos individuais e sociais. Deixaria a ONU de cumprir dever essencial se não cuidasse de proclamar quais sejam êsses direitos atestados pela conciência universal, e que se impõem a todos os Estados sob sanções da mesma conciência universal, numa ordem jurídica supra estatal, embora com sanções específicas, que cada povo não pode desconhecer sem destacar-se das contingências da hora política atual. 